\title{
Study on the Development of Diltiazem HCl Loaded Colonic Drug Delivery Systems (CDDS) Using Various Polymers and Characterization of their Release Profiles by In Vitro Dissolution Studies
}

\author{
Muhammad Shahidul Islam ${ }^{1}$, J akir Ahmed Chowdhury ${ }^{2}$ \\ and Shirajum Monira Tania ${ }^{3}$
}

\author{
${ }^{1}$ Department of Pharmacy, East West University, Dhaka, Bangladesh \\ ${ }^{2}$ Department of Pharmaceutical Technology, Faculty of Pharmacy, University of Dhaka, Dhaka-1000, Bangladesh \\ ${ }^{3}$ Department of Pharmacy, Stamford University Bangladesh, Dhaka
}

\begin{abstract}
This investigation describes the preparation and in vitro evaluation of Colonic Drug Delivery of Diltiazem HCl tablet. Methocel K 4M premium, Methocel K 100M premium CR, Methocel K 15M CR and Xanthan gum were used for release controlling properties. For this purpose, tablets containing $90 \mathrm{mg}$ of Diltiazem $\mathrm{HCl}$ along with different amounts of the aforementioned polymers were prepared using direct compression technique. All the formulations were then evaluated for thickness, hardness, diameter, weight variation and in vitro drug release characteristics as per USP monograph. Tablets prepared were placed in a basket type dissolution apparatus containing $\mathrm{HCl}$ solution ( $\mathrm{pH}-1.2)$ for the first 2 hours and phosphate buffer (pH-7.4) for the next 6 hours of the study. The amount of drug released was determined at $237 \mathrm{~nm}$ by a UV-visible spectrophotometer. Fitting of release data to different kinetic models showed that Methocel $\mathrm{K} 4 \mathrm{M}$ premium containing matrices conformed based to Korsmeyer release kinetics, Methocel K 100M CR based matrices to Korsmeyer and zero order, Methocel K 15M CR based matrices to zero order kinetics and Xanthan gum containing tablets to either of Higuchi and Korsmeyer release kinetics. The release exponent (n) derived from Korsmeyer-Peppas equation for the studied formulations implied that the release of Diltiazem $\mathrm{HCl}$ from Methocel K 4M premium based matrices and Methocel K 100M CR based formulations was Super case II transport mechanism. The value of release exponent (n) for Methocel K 15M CR containing matrices was mainly governed by Super case II transport. Xanthan gum based formulations was Anomalous/ Non-Fickian. Briefly, Methocel K 15M CR was found to be suitable for sustaining the release of Diltiazem $\mathrm{HCl}$ from matrix formulation inside the colon.
\end{abstract}

Key words: Colonic Drug Delivery, Direct Compression, Methocel K 4M premium, Methocel K 100M CR, Methocel K 15M CR, Xanthan gum.

\section{INTRODUCTION}

Sustained release dosage forms are used to achieve a prolonged therapeutic effect by continuously releasing medication over an extended period of time after administration of a single dose. In the case of orally administered forms, however,

\section{Correspondence to:}

Muhammad Shahidul Islam

Phone: +880-18-19559297

E-mail: shahid.pharmdu@gmail.com

Dhaka Univ. J. Pharm. Sci. 9(1): 7-13, 2010 (June) this period is measured in hours and critically depends on the residence time of the dosage form in the gastrointestinal (GI) tract. The term "Sustained release" has become associated with those systems from which therapeutic agents may be automatically delivered at predefined rates over a long period of time. ${ }^{1}$ Oral sustained release dosage form by direct compression technique is a very modern approach of drug delivery systems that proved demand in the pharmaceutical area as their easy, compliance, faster 
production, avoid hydrolytic or oxidative reaction occurred during processing of dosage forms. The colon is attracting interest as a site where poorly absorbed drug molecule may have an improved bioavailability. This region of the colon is recognized as having a somewhat less hostile environment with less diversity and intensity of activity than the stomach and small intestine. Additionally, the colon has a longer retention time and appears highly responsive to agents that enhance the absorption of poorly absorbed drugs. Apart from retarding or targeting dosage forms, a reliable colonic drug delivery could also be an important starting position for the colonic absorption of per orally applied, undigested, unchanged and fully active peptide drugs. As the large intestine is relatively free of peptidases such special delivery systems will have a fair chance to get their drug sufficiently absorbed after per oral application. ${ }^{2}$ The simplest method for targeting of drugs to the colon is to obtain slower release rates or longer release periods by the application of thicker layers of conventional enteric coatings or extremely slow releasing matrices. Diltiazem $\mathrm{HCl}$, a potent calcium channel blocker, is used in the management of angina pectoris, arrhythmia and hypertension. It has small plasma half-life and usual dose is $30 \mathrm{mg}$ thrice daily. As a result of its short half life, the development of oral sustained release formulation of this drug is highly desirable, so as to improve therapeutic effect with minimum side effects and improved patient compliance. ${ }^{3}$

\section{MATERIALS AND METHODS}

Diltiazem $\mathrm{HCl}$ was obtained from Eskayef Bangladesh Ltd. as a gift sample. Other materials used throughout the experiment were Methocel K 4M premium, Methocel K 100M CR, Methocel K 15M CR, Kollidon 30, Kollidon CL, Crosscarmelose Na $(\mathrm{SK}+\mathrm{F})$, Xanthan gum (Colorcon, USA), Ludipress (BASF, USA), Na starch glycolate (Merk, India), Talc, Aerosil (Degussa, Cobat, Germany) and Magnesium Stearate (Wilfrid Smith Ltd. UK.). All other reagents employed were of analytical or pharmaceutiacal grade.
Preparation of Colonic release tablets of Diltiazem $\mathrm{HCl}$ by Direct compression technique. For tablet preparation, method of dry blending of the active ingredients with polymers, filler, lubricant and flow promoter followed by direct compression was done. The active ingredient and other excipients were accurately weighted for 20 tablets according to the formulations. All the formulation materials, except lubricant and glidant (Magnesium stearate and aerosil) were sieved through 18-mesh and mixed well. The powder was then mixed with lubricant and glidant. The blend was then compressed by single punch tablet machine. All the preparations were stored in airtight containers at room temperature for further study.

Evaluation of granules. Carr's Index and Hausner Ratio. Both poured density (PD) and tapped density (TD) were determined. A quantity of $2 \mathrm{~g}$ of powder from each formula, previously lightly shaken to break any agglomerates formed, was introduced into a Pharmatest Densitometer (Germany) with 100 $\mathrm{ml}$ measuring cylinder. After the initial volume was observed, the cylinder was allowed to fall under its own weight onto a hard surface from the height of 2.5 $\mathrm{cm}$ at 2 second intervals. The tapping was continued until no further change in volume was noted. A useful empirical guide is given by Carr's Compressibility Index (equation 1). Tapped and poured densities of the powder mix of all formulations (without adding glident) were measured. A similar index (equation 2) has been defined by Hausner (1967). ${ }^{4}$

$$
\mathrm{CI}(\%)=(\mathrm{TD}-\mathrm{PD}) \mathrm{X} 100 / \mathrm{TD} \ldots \ldots \ldots(1)
$$

Hausner Ratio $=\mathrm{TD} / \mathrm{PD}$

Where, TD $=$ Tapped Density, PD $=$ Poured Density, CI = Carr's Index.

Angle of Repose. Angle of repose of the powder mix of all formulations (without adding glident) was determined according to the fixed funnel and freestanding cone method. A glass funnel $(75 \mathrm{~mm})$ was secured with its tip at a given height $(\mathrm{H})$ above a graph paper placed on a horizontal surface. Powder $(2.5 \mathrm{~g})$ was poured through the funnel until the apex 
of conical pile touched the tip of the funnel and then the angle of repose $(\theta)$ was calculated using the following formula (equation 3 ),

Tan $\theta=\mathrm{H} / \mathrm{R}$

Where $\mathrm{R}$ is the radius of conical pile which was measured by taking the radius of the circle (conical pile) ${ }^{5}$ produced by the powder mix on the graph paper.

Evaluation of Tablets. Hardness and tensile strength. Three tablets of each of the formulations were taken and hardness was measured by Hardness tester (Veego, India). The average value was calculated and the testing unit was $\mathrm{kg} / \mathrm{cm}^{2}$.

Thickness Measurement. Three tablets of each of the formulations were taken and thickness was measured by Vernier Caliper (E-Base Measuring Tools co., Taiwan). The values were reported in millimeter ( $\mathrm{mm}$ ).

Diameter Measurement: Three tablets of each of the formulations were taken and diameter was measured by Vernier Caliper. The values were reported in millimeter $(\mathrm{mm})$.

Friability Test. Four tablets of each of the formulations were weighed out and taken into the rotating disk of a Friability tester (Pharmatest, Germany). It was allowed to rotate at $25 \mathrm{rpm}$ for 4 minutes. At the end of the rotation, tablets were collected, dedusted and reweighed. The friability was calculated as the percent of weight loss.

In-vitro Dissolution study. The dissolution of sustained release Diltiazem tablets from preparing formula was monitored using standard BP apparatus basket equipment with the tablet positioned $3 \mathrm{~mm}$ above the bottom \& UV spectrophotometer, at 237 $\mathrm{nm}$. The compendially recommended stirring speed of $100 \mathrm{rpm}$ for the basket apparatus was used. The temperature was maintained at $37 \pm 0.5^{\circ} \mathrm{C}$ throughout. The apparatus was within specification for all six positions with regard to shaft wobble, alignment, rotation speed, vibration \& temperature. Firstly, acidic buffer (about $750 \mathrm{ml}$ ) was taken into six vessels $\&$ for each run, 6 tablets of two category of formula were placed into six vessels respectively for 2 hours.
After two hour $250 \mathrm{ml}$ of phosphate buffer was added in each vessel. These tablets were tested in phosphate buffer for 3 to 8 hours. The amount of drug released from the samples was then calculated with the help of appropriate calibration curve constructed from reference standards. Drug dissolved at specified time period was plotted as percent release versus time (hours) curve.

Kinetic modeling of drug release. The suitability of several equations that are reported in the literature to identify the mechanisms for the release of Diltiazem $\mathrm{HCl}$ was tested with respect to the release data. The data were evaluated according to the following equations:

$$
\begin{aligned}
& \text { Zero-order model: }{ }^{6} \\
& M_{t}=M_{0}+K_{0} t \ldots \ldots \ldots \ldots \ldots \ldots \ldots \\
& \text { Higuchi model: }{ }^{7,8} \\
& M_{t}=M_{0}+K_{H} t 0.5 \ldots \ldots \ldots \ldots \ldots \\
& \text { Korsmeyer-Peppas model: }{ }^{9,1} 10 \\
& M_{t}=M_{0}+K t_{n} \ldots \ldots \ldots \ldots \ldots \ldots \ldots
\end{aligned}
$$

Where $\mathrm{M}_{\mathrm{t}}$ is the amount of drug dissolved in time $t$, $\mathrm{M}_{0}$ is the initial amount of drug, $\mathrm{K}_{0}$ is the zero order release constant, $\mathrm{K}_{\mathrm{H}}$ is the Higuchi rate constant, $\mathrm{K}$ is a release constant, and $\mathrm{n}$ is the release exponent that characterizes the mechanism of drug release.

$$
\begin{aligned}
& \text { First order model. }{ }^{11} \\
& \log C=\log C_{0}-k t / 2.303 .
\end{aligned}
$$

Where, $\mathrm{C}=$ cumulative percent of drug release at time $t, C_{o}=$ the initial concentration of drug at $t=0$ and $\mathrm{k}=$ first order rate constant.

\section{RESULTS AND DISCUSSION}

The granules of different formulations were evaluated for angle of repose, PD, TD, Carr's index and Hausner ratio (Table 1). The results of angle of repose and Carr's index (\%) ranged from 28.25 to 30.68 and 12.65 to 21.89 respectively. Hausner ratio was from 1.14 to 1.28 . The average diameter and thickness of the tablets was 10.81 and $2.51 \mathrm{~mm}$ respectively. The average hardness from 6.4 to 7.1 $\mathrm{kg} / \mathrm{cm}^{2}$. The average $\%$ friability was found less than 
$0.24 \%$. The release rate of colonic release Diltiazem $\mathrm{HCl}$ in first two hours in acid media was so negligible (less than 1\%), that's why the result was not shown in the release curve (Figure 1).

Table 1. Properties of granules (values are expressed as mean).

\begin{tabular}{lccc}
\hline $\begin{array}{l}\text { Formulation } \\
\text { Code }\end{array}$ & $\begin{array}{c}\text { Average } \\
\text { Angle of } \\
\text { repose }(\theta)\end{array}$ & $\begin{array}{c}\text { Average } \\
\text { Carr's } \\
\text { Index }(\%)\end{array}$ & $\begin{array}{c}\text { Average } \\
\text { Hausner } \\
\text { Ratio }\end{array}$ \\
\hline Formula-1 & 28.68 & 12.65 & 1.14 \\
Formula-2 & 28.97 & 12.89 & 1.16 \\
Formula-3 & 29.19 & 15.18 & 1.20 \\
Formula-4 & 29.53 & 17.71 & 1.22 \\
Formula-5 & 30.14 & 20.37 & 1.27 \\
Formula-6 & 30.68 & 21.89 & 1.28 \\
Formula-7 & 28.25 & 14.51 & 1.18 \\
Formula-8 & 28.65 & 14.65 & 1.19 \\
\hline
\end{tabular}

To investigate the effects of polymer and their content level on drug release eight formulations were prepared (Table 2). Formulation F-1, F-2 and F- 3 fit with Korsmeyer kinetic model $\left(\mathrm{R}^{2}=0.9887\right.$, $\mathrm{R}^{2}=0.9919$ and $\mathrm{R}^{2}=0.992$ respectively) (Table 4$)$. The values of release exponent (n) for the above mentioned formulations are 1.0306, 0.8604 and 0.8621 respectively which indicates super case II transport mechanism. F-4 $\left(\mathrm{R}^{2}=0.9904\right)$ has a value of release exponent (n) is 0.9947 which indicates super case II transport, i.e. the drug release rate does not change over time and the release is characterized by zero order. F-5 and F-6 followed zero order release kinetics $\left(\mathrm{R}^{2}=0.9969\right.$ and $\left.\mathrm{R}^{2}=0.9926\right)$ (Table 4). The values of release exponent (n) for the formulation F-5 and F-6 are 1.0306, and 0.8604 respectively, which indicates drug release is followed by super case II transport mechanism. F-7 $\left(\mathrm{R}^{2}=0.9686\right)$ and F-8 $\left(\mathrm{R}^{2}=0.9772\right)$ has a value of release exponent $(\mathrm{n})$ is 0.7966 and 0.8067 , which indicates the drug release is dominated by anomalous transport.

Table 2. Formulations of Colonic release Diltiazem HCl tablets prepared by direct compression method.

\begin{tabular}{lcccccccc}
\hline \multirow{2}{*}{$\begin{array}{l}\text { Ingredients } \\
(\mathrm{mg})\end{array}$} & F-1 & F-2 & F-3 & F-4 & F-5 & F-6 & F-7 & F-8 \\
\cline { 2 - 9 } Diltiazem HCl & 90 & 90 & 90 & 90 & 90 & 90 & 90 & 90 \\
M K 4M Premium & 55 & 65 & - & - & - & - & - & - \\
M K 100 Premium CR & - & - & 55 & 65 & - & - & - & - \\
M K 15M CR & - & - & - & - & 55 & 65 & - & - \\
Xanthan Gum & - & - & - & - & - & - & 55 & 65 \\
Povidone (Kollidon 30) & 10 & 10 & 10 & 10 & 10 & 10 & 10 & 10 \\
Ludipress & 100 & 100 & 100 & 100 & 100 & 100 & 100 & 100 \\
Cross Carmelose Na & 45 & 35 & - & - & - & - & 10 & 15 \\
Na-Starch Gltcolate & - & - & 45 & 35 & - & - & 15 & 12 \\
Kollidone CL (Crosspovidone) & - & - & - & - & 45 & 35 & 20 & 8 \\
Aerosil & 3 & 3 & 3 & 3 & 3 & 3 & 3 & 3 \\
Talc & 2 & 2 & 2 & 2 & 2 & 2 & 2 & 2 \\
Mg-Stearate & 2 & 2 & 2 & 2 & 2 & 2 & 2 & 2 \\
Total & 310 & 310 & 310 & 310 & 310 & 310 & 310 & 310 \\
\hline
\end{tabular}

Table 3. Physical Parameters of Colonic release Diltiazem HCl tablets.

\begin{tabular}{lcccccc}
\hline $\begin{array}{l}\text { Formulation } \\
\text { code }\end{array}$ & $\begin{array}{c}\text { Average Hardness } \\
\left(\mathrm{Kg} / \mathrm{cm}^{2}\right)\end{array}$ & $\begin{array}{c}\text { Friability } \\
(\%)\end{array}$ & $\begin{array}{c}\text { Average } \\
\text { Thickness }(\mathrm{mm})\end{array}$ & $\begin{array}{c}\text { Average } \\
\text { Diameter }(\mathrm{mm})\end{array}$ & $\begin{array}{c}\text { Average tablet } \\
\text { wt. }(\mathrm{mg})\end{array}$ & $\begin{array}{c}\text { Weight } \\
\text { variation }(\%)\end{array}$ \\
\hline F-1 & 6.5 & 0.3 & 2.9 & 10.74 & 309.89 & 0.03 \\
F-2 & 6.8 & 0.18 & 2.7 & 10.76 & 310.06 & 0.01 \\
F-3 & 6.4 & 0.4 & 2.47 & 10.90 & 310.13 & 0.04 \\
F-4 & 6.7 & 0.3 & 2.6 & 10.89 & 309.91 & 0.02 \\
F-5 & 6.8 & 0.25 & 2.14 & 10.91 & 310.09 & 0.02 \\
F-6 & 7 & 0.2 & 2.52 & 10.90 & 309.82 & 0.05 \\
F-7 & 6.9 & 0.2 & 2.50 & 10.73 & 310.03 & 0.009 \\
F-8 & 7.1 & 0.1 & 2.25 & 10.69 & 309.91 & 0.02 \\
\hline
\end{tabular}


Table 4. Kinetic parameters of Colonic release Diltiazem HCl

\begin{tabular}{lcccccccc}
\hline \multirow{2}{*}{$\begin{array}{l}\text { Formulation } \\
\text { code }\end{array}$} & $\begin{array}{c}\text { \% of drug release } \\
\text { after 8 hrs }\end{array}$ & \multicolumn{2}{c}{ Zero Order } & \multicolumn{2}{c}{ Higuchi } & \multicolumn{2}{c}{ Korsmeyer } & Mean Dissolution \\
\cline { 3 - 7 } & $\mathrm{K}_{\mathrm{o}}$ & $\mathrm{R}^{2}$ & $\mathrm{~K}_{\mathrm{H}}$ & $\mathrm{R}^{2}$ & $\mathrm{n}$ & $\mathrm{R}^{2}$ & Time (MDT) (hrs) \\
\hline F-1 & 88.00 & 11.458 & 0.979 & 31.488 & 0.9255 & 1.0306 & 0.9887 & 5.6303 \\
F-2 & 81.96 & 10.437 & 0.9637 & 29.55 & 0.966 & 0.8604 & 0.9919 & 6.4346 \\
F-3 & 76.14 & 9.5983 & 0.9913 & 26.62 & 0.9535 & 0.8621 & 0.9992 & 4.7928 \\
F-4 & 70.40 & 8.9904 & 0.9904 & 24.206 & 0.9134 & 0.9947 & 0.9843 & 5.4368 \\
F-5 & 72.38 & 8.9427 & 0.9969 & 24.206 & 0.9134 & 1.0306 & 0.9887 & 5.6303 \\
F-6 & 60.59 & 7.4877 & 0.9926 & 20.708 & 0.9495 & 0.8604 & 0.9919 & 6.4346 \\
F-7 & 80.92 & 10.32 & 0.9656 & 29.251 & 0.9686 & 0.7966 & 0.955 & 4.0532 \\
F-8 & 73.13 & 9.3884 & 0.9739 & 26.452 & 0.9668 & 0.8067 & 0.9772 & 4.6492 \\
\hline
\end{tabular}
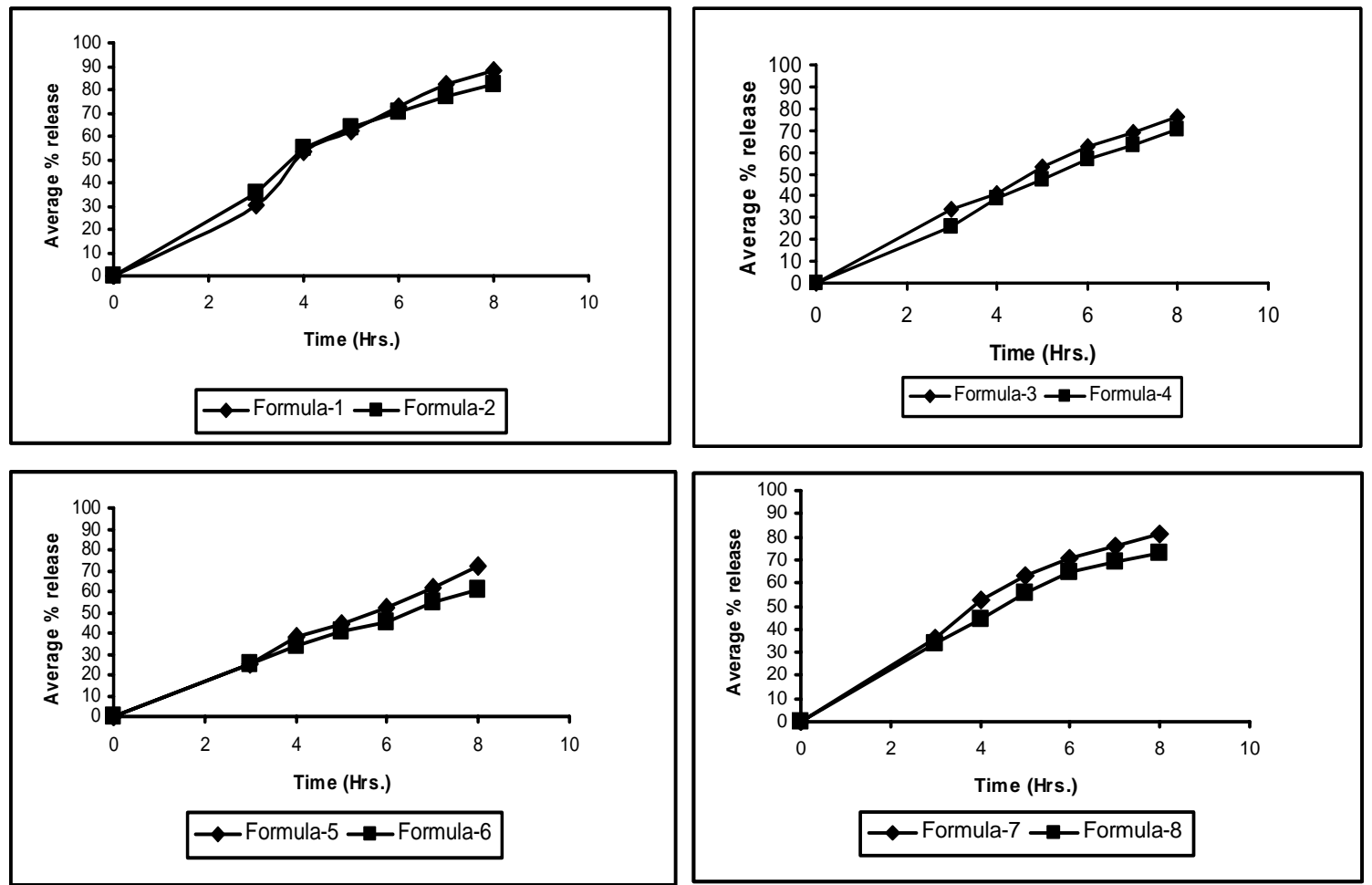

Figure 1. Zero order release profile showing effect of polymers on Diltiazem HCl release from 1(a) Methocel K4M 1(b) Methocel K100M 1(c) Methocel K15M CR 1(d) Xanthan gum based tablets.

The mean dissolution time (MDT) value is used to characterize the drug release rate from the dosage form and the retarding efficacy of the polymer. A higher value of MDT indicates a higher drug retarding ability of the polymer and vice versa. The MDT value was also found to be a function of polymer content and polymer nature. MDT values for all the eight formulas are listed in Table 4. From the table, it was observed that, MDT values were larger for those formulations which contained highest percentage of polymer.

Effects of Methocel K 4M premium polymer on the release profile of Diltiazem $\mathrm{HCl}$ matrix tablet. From the figure 1(a) release profile of Diltiazem $\mathrm{HCl}$ from Methocel $\mathrm{K} 4 \mathrm{M}$ premium matrix tablet of two different formulations was obtained. After 8 hours the total percent release of Diltiazem $\mathrm{HCl}$ from Formulation-1 and Formulation-2 was $88 \%$ 
and $82 \%$. So, it was observed that drug release rate has been decreased with increase in the amount of Methocel K 4M premium.

The highest percent of drug release within 8 hours is from Formulation-1 where Methocel K 4M premium content is $55 \%$. But in Formulation-2, which contains highest amount of polymer, Diltiazem $\mathrm{HCl}$ released from that formulation was $82 \%$ within 8 hours. This may be also due to the poor solubility of Diltiazem $\mathrm{HCl}$ in water, besides the physico-chemical properties of the polymers used, mentioned above.

Effects of Methocel K 100M CR polymer on the release profile of Diltiazem $\mathrm{HCl}$ tablet. The release profile of Diltiazem $\mathrm{HCl}$ from Methocel $\mathrm{K}$ 100M CR matrix tablet of two different formulations was showed in figure 1(b). After 8 hours the total percent release of Diltiazem $\mathrm{HCl}$ from Formulation-3 and Formulation- 4 was $76 \%$ and $70 \%$. So, it was observed that drug release rate has been decreased with increase in the amount of Methocel K 100M CR.

The highest percent of drug release within 8 hours is from Formulation-3 where Methocel $\mathrm{K}$ $100 \mathrm{M}$ CR content is $55 \%$. But in Formulation-4, which contains highest amount of polymer, Diltiazem $\mathrm{HCl}$ released from that formulation was $70 \%$ within 8 hours.

Effects of Methocel K 15M CR polymer on the release profile of Diltiazem $\mathrm{HCl}$ tablet. The release profile of Diltiazem $\mathrm{HCl}$ from Methocel K15M CR matrix tablet of two different formulations was showed in figure 1(c). After 8 hours the total percent release of Diltiazem $\mathrm{HCl}$ Formulation-5 and Formulation-6 was $72 \%$ and $60 \%$. So, it was observed that drug release rate has been decreased with increase in the amount of Methocel K15M CR.

The highest percent of drug release within 8 hours is from Formulation-5 where polymer content is 55\%. But in Formulation-6 which contains highest amount of polymer than all the formulations Diltiazem $\mathrm{HCl}$ was released from that formulation $60 \%$ within 8 hours.
Effects of Xanthan Gum on the release profile of Diltiazem HCl tablet. The release profile of Diltiazem $\mathrm{HCl}$ from Xanthan Gum based tablet of two different formulations was showed in figure 1(d). After 8 hours the total percent release of Diltiazem $\mathrm{HCl}$ from Formulation-7 and Formulation- 8 was $81 \%$ and $73 \%$. So, it was observed that drug release rate has been decreased with increase in the amount of Xanthan Gum.

The highest percent of drug release within 8 hours is from Formulation-7 where polymer content is $55 \%$. But in Formulation-8, which contains highest amount of polymer than all the formulations Diltiazem $\mathrm{HCl}$ was released from that formulation $73 \%$ within 8 hours.

\section{CONCLUSION}

Oral delivery of drugs to the colon is valuable in the treatment of diseases of colon (ulcerative colitis, Chron's disease, carcinomas and infections) whereby high local concentration can be achieved while minimizing side effects that occur because of release of drugs in the upper GIT or unnecessary systemic absorption. Sustained release dosage form is mainly designed for maintaining therapeutic blood or tissue levels of the drug for extended period of time with minimize local and systemic adverse effects. Sustained release dosages forms would be most applicable for drugs having low therapeutic indices and short elimination half lives. Diltiazem $\mathrm{HCl}$ has small plasma half -life. As a result of short half-life, the development of oral sustained release formulation of this drug is highly desirable. Diltiazem $\mathrm{HCl}$ is a most effective sustained release colonic drug. As a colonic release drug, Diltiazem $\mathrm{HCl}$ tablets slowly release drug for a longer period of a time in the colon. The influence of dissolution media on the release rate was significant and found to be highest in phosphate buffer than in acidic media. The release data were then treated in different mathematical model to identify the release mechanism. At present, all the polymers being studied are used extensively in pharmaceuticals to control the release of drug. The approach of the present study was to make a 
comparative evaluation among the percent of polymer and to assess the effect of polymers on release profile of formulated drug Diltiazem $\mathrm{HCl}$. The study reveals that the drug release of F-1 \& F-2 were better than other formulations in basic media. From the above discussion, the experiment indicates that, Diltiazem $\mathrm{HCl}$ tablet delivered drug at desired rate in the colon. The rate and extent of drug release of different formulations were different but fully in agreement with the USP specification. This experiment also indicates that, the rate and extent of drug release could be modulated accordingly by varying amount of release modifier.

\section{REFERENCES}

1. Lordi, N.G. 1987.Sustained Release Dosage Forms, in Lachman L: Lieberman $\mathrm{H} \mathrm{A}$ and Kanig J L (eds). The Theory and Practice of Industrial Pharmacy. $3^{\text {rd }}$ ed., Varghese Publishing House, Bombay, pp. 430-456.

2. Chourasia, M.K. and Jain, S.K. 2003. Pharmaceutical approaches to colon targeted drug delivery systems. J Pharm Pharmaceut Sci. 6, 33-66.

3. Chaffman, M. and Brogden, R. N. (1985). Diltiazem, a review of its pharmacological properties and therapeutic efficacy. Drugs. 29, 387-454.

4. Wells, J.E. and Aulton, M.E. 1998. In: Pharmacutics: The Dosage Form Design, (Aulton, M.E ed.), Churchill Livingstone, Edinburgh. Chapter 13, pp. 247-248.
5. Abdelkader, H., Abdalla, O.Y. and Salem H. 2007. Formulation of Controlled Release Baclofen Matrix Tablets: Influence of Some Hydrophilic Polymers on the Release Rate and In Vitro Evaluation. AAPS Pharm. Sci. Tech. 8, Article 100 .

6. Donbrow, M. and Samuelov, Y. 1980. Zero order drug delivery from double layered porous films: release rate profiles from ethylcellulose, hydroxypropylcellulose and polyethylene glycol mixtures. J. Pharm. Pharmacol. 32, 463- 470 .

7. Higuchi, T. 1961. Rate of release of medicaments from ointment bases containing drugs in suspension. J. Pharm. Sci. 50, 874-875.

8. Higuchi, T. 1963. Mechanism of sustained-action medication: theoretical analysis of rate of release of solid drugs dispersed in solid matrices. J. Pharm. Sci. 52, 11451149 .

9. Korsmeyer, R.W., Gurny, R., Doelker, E.M., Buri, P. and Peppas, N.A. 1983. Mechanism of solute release from porous hydrophilic polymers. Int. J. Pharm. 15, 25-35.

10. Peppas, N.A. 1985. Analysis of Fickian and non-Fickian drug release from polymers. Pharm. Acta. Helv. 60, 110-111.

11. Merchant, H.A., Shoaib, H.M., Tazeen, J. and Yousuf, R.I. 2006. Once-Daily tablet formulation and in vitro release evaluation of Cefpodoxime using Hydroxypropyl Methylcellulose: A Technical note. AAPS Pharm. Sci. Tech.. 7, Article 78. 